\title{
Assessing RET/PTC in thyroid nodule fine-needle aspirates: the FISH point of view
}

\author{
Paola Caria', Tinuccia Dettori', Daniela V Frau', Angela Borghero' ${ }^{2}$, Antonello Cappai ${ }^{2}$, \\ Alessia Riola ${ }^{2}$, Maria L Lai ${ }^{3}$, Francesco Boi $^{2}$, Piergiorgio Calo ${ }^{3}$, Angelo Nicolosi ${ }^{3}$, \\ Stefano Mariotti ${ }^{2}$ and Roberta Vanni ${ }^{1}$
}

Departments of ${ }^{1}$ Biomedical Sciences ${ }^{2}$ Medical Sciences 'M. Aresu' ${ }^{3}$ Surgical Sciences, University of Cagliari, Cittadella Universitaria, 09042 Monserrato (Cagliari), Italy
Correspondence should be addressed to R Vanni

Email

vanni@unica.it

\begin{abstract}
RETIPTC rearrangement and $B R A F^{V 600 E}$ mutation are the two prevalent molecular alterations associated with papillary thyroid carcinoma (PTC), and their identification is increasingly being used as an adjunct to cytology in diagnosing PTC. However, there are caveats associated with the use of the molecular approach in fine-needle aspiration (FNA), particularly for RETIPTC, that should be taken into consideration. It has been claimed that a clonal or sporadic presence of this abnormality in follicular cells can distinguish between malignant and benign nodules. Nevertheless, the most commonly used PCR-based techniques lack the capacity to quantify the number of abnormal cells. Because fluorescence in situ hybridization (FISH) is the most sensitive method for detecting gene rearrangement in a single cell, we compared results from FISH and conventional RT-PCR obtained in FNA of a large cohort of consecutive patients with suspicious nodules and investigated the feasibility of setting a FISH-FNA threshold capable of distinguishing non-clonal from clonal molecular events. For this purpose, a home brew break-apart probe, able to recognize the physical breakage of $R E T$, was designed. While a $\geq 3 \%$ FISH signal for broken $R E T$ was sufficient to distinguish nodules with abnormal follicular cells, only samples with a $\geq 6.8 \%$ break-apart FISH signal also exhibited positive RT-PCR results. On histological analysis, all nodules meeting the $\geq 6.8 \%$ threshold proved to be malignant. These data corroborate the power of FISH when compared with RT-PCR in quantifying the presence of RETIPTC in FNA and validate the RT-PCR efficiency in detecting clonal RETIPTC alterations.
\end{abstract}

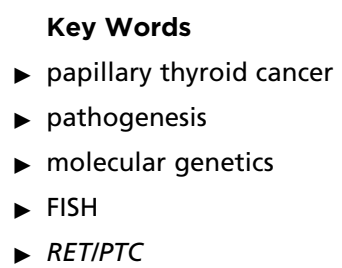

Endocrine-Related Cancer (2013) 20, 527-536

\section{Introduction}

A multi-method approach, including cytology, immunohistochemistry, and molecular testing, seems to be the best choice for presurgical determination of the malignant potential of thyroid nodules (Mehta et al. 2012). Expanding knowledge regarding the molecular pathways implicated in papillary thyroid carcinoma (PTC) pathobiology has revealed that $B R A F^{V 6 O 0 E}$ mutation, rearrangements of the tyrosine kinase receptor genes RET and TRK (NTRK1), and $R A S$ mutations play material roles in the pathogenesis of most PTCs (Santoro et al. 2006, Xing 2007). Consequently, the use of some of these abnormalities as tumor biomarkers is being translated into clinical practice, and their preoperative examination is increasingly being used as an adjunct to cytology. As these abnormalities rarely

Published by Bioscientifica Ltd 
coexist in an individual PTC, testing for multiple alterations may improve the sensitivity of the molecular diagnosis. In this regard, a few gene classifiers are now commercially available, claiming enhanced performance in the presurgical diagnosis of thyroid nodules (Ali et al. 2013). Nevertheless, some caveats should be taken into account when considering the molecular approach, and the need for a general consensus on this issue has also risen recently (Hodak et al. 2013). Detection methods, as well as intratumoral genetic heterogeneity, may in fact influence the diagnostic significance of the results. Multiple detection methods have highlighted a consistent variability in the prevalence of RET/PTC oncogene activation in surgically removed thyroid nodules (Zhu et al. 2006), and heterogeneity in the distribution of PTC-specific alterations within a nodule is frequent. Intranodular coexistence of wild-type and mutated subclones has been observed in individual nodules (Fusco et al. 2002, Unger et al. 2004, Caria et al. 2012, Guerra et al. 2012). Furthermore, RET/PTC activation in adenomas (Ishizaka et al. 1991, Guerra et al. 2011) and in the non-tumoral follicular cells of patients with Hashimoto's thyroiditis (Rhoden et al. 2006) has been reported; thus, the biological significance of this oncogene has yet to be clarified (Fagin 2004, Nikiforov 2006, Arora et al. 2008).

RET/PTC oncogene expression in follicular cells challenges the objectivity of diagnostic interpretation (Zhu et al. 2006, Marotta et al. 2011) because on the one hand, it has a higher rate of lymph node metastases (Adeniran et al. 2006), while on the other hand, it may not be exclusively found in malignancy and often occurs only in a proportion of tumor cells. Interphase fluorescence in situ hybridization (FISH) is the gold standard method for detecting gene rearrangements in a single cell and is the most sensitive means for identifying and quantifying intratumoral genetic heterogeneity (Nakazawa et al. 2009, Drieschner et al. 2011, Hieber et al. 2011). However, as FISH requires expert operators and is a time-consuming technology, it is rarely used, and no FISH-based studies on fine-needle aspiration (FNA) have been reported. At present, the detection of RET/PTC in FNA material, including smears (Ferraz et al. 2012), principally relies on PCR-based methods. In view of these observations, we sought to explore the meaning and limits of the achievable results for RET/PTC in thyroid nodule FNA. We used both FISH and RT-PCR technologies to investigate the possible significance of finding different proportions of cells with RET/PTC alterations in thyroid nodule FNA. We compared results from FISH analysis using a home brew break-apart RET probe with results achieved by conventional RT-PCR in a large series of thyroid FNA. In addition, FNA were investigated for $B R A F^{V 600 E}$ mutation to ascertain possible overlap between the two molecular alterations. Surgically removed nodules showing broken RET in the corresponding FNA were also investigated by FISH in order to better define the platform sensitivity.

\section{Subjects and methods}

\section{Samples}

Biological material was collected from 329 nodules from 261 patients seen consecutively at the Endocrine Unit of Cagliari University Hospital (Azienda OspedalieroUniversitaria). Written informed consent was obtained from all patients before FNA. Ultrasound-guided FNA was performed according to international guidelines (Cooper et al. 2009) using 22- to 25-gauge needles attached to a $10 \mathrm{ml}$ syringe, with two to four passes for each nodule, as described previously (Boi et al. 2005). Samples were collected from August 2009 to October 2010.

A minimum of five direct smears were prepared. All smears except one (or more if available) were fixed in alcohol and used for cytological analysis. The remaining smears were air dried and used to investigate RET physical integrity/breakage (indicative of the absence/presence of RET/PTC variants) by FISH, employing a dual-color, breakapart strategy. Total RNA isolated from residual FNA material was used for RT-PCR for RET/PTC analysis and for DNA isolation to investigate $B R A F^{V 600 E}$ mutation by real-time RT-PCR. FISH evaluation was performed on 281 suitable nodules (85.4\%). RET/PTC3 was tested in instances of conflicting results between FISH and RET/PTC1. The study was carried out in accordance with the protocols approved by the review board and in compliance with the Declaration of Helsinki, http:// www.wma.net/en/30publications/10policies/b3.

\section{FNA and histology}

Cytology of nodules (all with FISH available results) was classified as follows: inadequate sample, Thy $1(n=12$, $4.3 \%)$; benign, Thy 2 ( $n=189,67.3 \%)$; indeterminate, Thy $3(n=46,16.4 \%)$; suspicious of malignancy, Thy 4 $(n=15,5.3 \%)$; or malignant, Thy $5(n=19,6.8 \%)$, according to the British Thyroid Association, the Italian Society of Anatomic Pathology, and diagnostic cytology consensus. Criteria for selecting patients for thyroid surgery were as follows: total or near-total thyroidectomy

Published by Bioscientifica Ltd. 
was always advised for all patients with a cytological class Thy 5 or Thy 4 and was suggested for patients with Thy 3 cytology. Surgery was also suggested for patients with Thy 2 cytology in the presence of large nodules and/or compressive symptoms. Cytology and histology were performed by an experienced pathologist (M L L), who was unaware of genetic/molecular results.

Thyroid specimens were fixed with $10 \%$ buffered formalin. Each nodule was totally or subtotally sampled (with at least ten sections including capsule) and embedded in paraffin. Serial slides stained with hematoxylin-eosin were examined. The presence of benign or malignant neoplasia, as well as non-neoplastic lesions, was determined using common criteria.

\section{Probes, probe validation, and cutoff}

To test possible breakage of the RET gene resulting from chromosomal structural rearrangements (either inversion 10q11.2 or translocations involving this band), a dual-color, break-apart probe employing labeled DNA of bacterial artificial chromosome (BAC) clones flanking the RET gene. BACs were selected from the UCSC Human Genome Browser (http://genome.cse.ucsc.edu) and obtained from BAC/PAC Resources (http://www.chori.org/). Two different fluorophores were used to prepare a dual-color, break-apart probe (Wolff et al. 2007): BAC clones RP11686A03 and RP11-290I03 (for the proximal breakpoint), spanning $272.9 \mathrm{~kb}$, labeled by nick translation with Spectrum Red (Abbott Molecular/Vysis, Downers Grove, IL, USA), and two BAC clones RP11-818P01 and RP11696N03 (for the distal breakpoint), spanning $351.5 \mathrm{~kb}$, labeled by Spectrum Green (Abbott Molecular/Vysis) were pooled to yield strong FISH signals. The two differently labeled sets were co-hybridized as described (Frau et al. 2010), resulting in two pairs of adjacent/overlapping red and green FISH signals in cells with unbroken RET and red and green split-apart FISH signals in cells with gene breakage (Caria \& Vanni 2010).

Dual-color, dual-fusion probes (Wolff et al. 2007) (BAC RP11-351D16, containing the RET gene labeled with Spectrum Red, and BAC RP11-481A12, containing the NCOA4 gene labeled with Spectrum Green) (Abbott Molecular/Vysis) were used to test the possible presence of a RET/PTC3 rearrangement in instances of conflicting results between FISH and RT-PCR for RET/PTC. Cells with RET/PTC3 have one red (RET) and one green (NCOA4) signal plus two fused red/green signals (rearranged RET/NCOA4).
Analytical specificity (percentage of FISH signal located at the correct metaphase chromosome position of RET gene, 10q11.2) and sensitivity (percentage of metaphases or nuclei with FISH signal) of the break-apart RET probe were tested on 209 metaphases and 800 interphase nuclei from phytohemagglutinin-stimulated lymphocyte cultures (in DMEM/F12 medium with additives) (Gibco/Life Technologies) derived from apparently healthy male volunteers. Specificity and sensitivity values were 100 and $99.5 \%$ respectively.

In a subsequent experiment, we tested split FISH signals on 2000 nuclei isolated from fixed paraffinembedded tissue samples (see FISH paragraph for technical details) from the apparently tumor-free contralateral lobe of five PTCs negative for RET/PTC by conventional RT-PCR. The cutoff value for correctly identifying normal thyroid samples, calculated as the beta inverse function (Wiktor et al. 2006), was a split-apart FISH signal in $2.4 \%$ of cells. On the basis of this, a sample was considered negative for broken RET when a split-apart FISH signal was observed in $<3 \%$ of nuclei and, conversely, positive when it was observed in $\geq 3 \%$ of nuclei. Although the cutoff by beta inverse function is reported as the most appropriate statistical approach for results not fitting with a Gaussian distribution (Wiktor et al. 2006), we also calculated the mean +3 s.D. of split FISH signals, which was $3.0 \%$, confirming the value of $\geq 3 \%$ as the positivity threshold.

\section{FISH analysis}

For prospective analysis, unfixed cytological smears were kept at $-30^{\circ} \mathrm{C}$ until use. For postoperative FISH testing, either nuclei from touch preparations or nuclei isolated from formalin-fixed paraffin-embedded (FFPE) tumor tissue from thyroidectomy were used. Nuclei were isolated from FFPE using a method modified from Petersen et al. (2004). Briefly, $30 \mu \mathrm{m}$ tissue sections were deparaffinized using xylene (twice for $10 \mathrm{~min}$ ), rehydrated through an ethanol series, and incubated in distilled water overnight at $4{ }^{\circ} \mathrm{C}$. Sections were digested for $60-90 \mathrm{~min}$ in a $0.05 \%$ trypsin solution. The enzymatic reaction was stopped by adding FCS to $10 \%$ (v/v) (Gibco/Life Technologies). Nuclei were collected by centrifugation, washed in PBS, resuspended in 50-100 $\mu \mathrm{l} \mathrm{PBS,} \mathrm{and} \mathrm{gently} \mathrm{dropped}$ onto clean slides. Air-dried slides were dehydrated in an ethanol series and either used immediately or stored at $-30{ }^{\circ} \mathrm{C}$.

Cytological smears and isolated nuclei preparations were pretreated and hybridized to probes as described

Published by Bioscientifica Ltd 
(Frau et al. 2010). A mean of 67 (range: 30-362) non-overlapping nuclei, counterstained with $4^{\prime}$,6-diamidino-2-phenylindole, were scored per case. Microscopic analysis was performed with an Olympus BX41 epifluorescence microscope and a charge-coupled device camera (Cohu, San Diego, CA, USA) interfaced with the CytoVision system (software version 3.9; Applied Imaging, Pittsburg, PA, USA). To avoid misinterpretation due to artifacts, the distance between two separated signals of the break-apart probe was estimated using the two times of biggest signal size (Kim et al. 2006).

\section{RNA isolation and RT-PCR}

Total RNA was isolated from FNA by RNeasy Mini Kit (Qiagen). Quantitation was performed on a Qubit fluorometer (Invitrogen/Life Technologies) using a Quant-iT RNA assay kit (Invitrogen/Life Technologies). RET/PTC1 rearrangements were detected by RT-PCR. RT-PCR was followed by agarose gel electrophoresis. Briefly, $20 \mathrm{nM}$ total RNA were reverse transcribed using a QuantiTect Reverse Transcription Kit (Qiagen) according to the manufacturer's protocol. cDNA samples (15 ng) were amplified using a Platinum Taq Kit (Invitrogen/Life Technologies) with the following specific primers for RET/PTC1 amplification: forward, 5'-GTCGGGGGGCATTGTCATCT-3'; reverse, 5'-AAGTTCTTCCGAGGGAATTC- $3^{\prime}$. Cycling conditions were: denaturation for 2 min at $95^{\circ} \mathrm{C}$, followed by 40 cycles of amplification with denaturation for $20 \mathrm{~s}$ at $95^{\circ} \mathrm{C}$, annealing for $30 \mathrm{~s}$ at $55^{\circ} \mathrm{C}$, and extension for $1 \mathrm{~min}$ at $72^{\circ} \mathrm{C}$. All samples were assessed for cDNA adequacy by amplification of a positive control sample, housekeeping gene, and molecular weight marker. PCR products were electrophoresed on a $2 \%$ UltraPure agarose gel (Invitrogen/Life Technologies) in TBE $1 \times$ and visualized by Syber Safe (Invitrogen/Life Technologies).

\section{Real-time PCR}

Genomic nucleic acid was isolated from FNA samples using a QIAmp DNA Mini Kit (Qiagen). Quantification of genomic DNA was done by Qubit fluorometer (Invitrogen/Life Technologies) using Quant-iT ds DNA HS (Invitrogen/Life Technologies). PCR primers were based on the wild-type exon 15 of the $B R A F$ gene: forward, 5'-TAGTACACCTCAGATATAT-3'; reverse, 5'-AAATAGCCTCAATTCTTAC- $3^{\prime}$. Conditions for RT-PCR were optimized for Real Time PCR IQ5 instrument (Bio-Rad), utilizing Fluorescent TaqMan LNA probes (Sigma/Aldrich) for wild-type exon 15 and for $B R A F^{V 600 E}$ exon 15 . The reaction mixture contained $10 \mathrm{ng}$ genomic DNA, $12.5 \mu \mathrm{l}$ Super Mix $2 \times$ (Bio-Rad), $10 \mathrm{mM}$ each specific primer (Invitrogen/Life Technologies), and $10 \mathrm{mM}$ fluorescent probes: hex-CTA $(+\mathrm{C}) \mathrm{AG}(+\mathrm{T}) \mathrm{GA}(+\mathrm{A}) \mathrm{A}(+\mathrm{T}) \mathrm{CT}$ (bhq1) for $B R A F^{V 600 E}$ exon 15 and 6-fam-CTA $(+\mathrm{C}) \mathrm{AG}$ $(+\mathrm{A}) \mathrm{GA}(+\mathrm{A}) \mathrm{A}(+\mathrm{T}) \mathrm{CT}(\mathrm{bhq} 1)$ (Sigma/Aldrich) for wildtype exon 15 , in a final volume of $25 \mu$ l. Cycling conditions were denaturation for $5 \mathrm{~min}$ at $95^{\circ} \mathrm{C}, 45$ cycles of amplification with denaturation for $5 \mathrm{~min}$ at $95^{\circ} \mathrm{C}$, annealing for $30 \mathrm{~s}$ at $53^{\circ} \mathrm{C}$, and extension for $30 \mathrm{~s}$ at $72^{\circ} \mathrm{C}$. In each quantitative RT-PCR (qPCR) procedure, positive and negative controls and housekeeping genes were also amplified.

Confirmation of mutation was effected by direct sequencing utilizing BigDye ver. 1.1 terminator kit (Applied Biosystems), specific amplification primers for exon 15 (Invitrogen/Life Technologies), and an ABI 310 Genetic Analyzer (Applied Biosystems).

\section{Statistical analysis}

The FISH cutoff value was calculated as both the beta inverse function (Wiktor et al. 2006) and the mean+3s.D. value. Results are reported as sensitivity, true positive/ (true positive + false negative); specificity, true negative/ (true negative + false positive); accuracy (true positive + true negative)/all samples examined; positive predictive value, true positive/(true positive + false positive); and negative predictive value, true negative/(true negative + false negative). Values were calculated using MedCalc for Windows, version 12.5 (MedCalc Software, Ostend, Belgium).

\section{Results}

\section{Samples}

Of 329 available nodules, 281 gave suitable FISH results $(85.4 \%)$ and were investigated by cytology, RT-PCR for $R E T / P T C$ rearrangement, and qPCR and direct sequencing for $B R A F^{V 600 E}$ mutation. None of the patients were advised to undergo surgery on the basis of a positive RET rearrangement.

\section{Cytology and histology of RET/PTC-positive cases}

Cytological and histological results are reported in Table 1. The comparison between cytological and histological results of thyroid nodules was based on clinical and ultrasound preoperative findings. Incidental microscopic

Published by Bioscientifica Ltd 
Table 1 FISH-ascertained and RT-PCR-ascertained broken RET in FNA

\begin{tabular}{|c|c|c|c|c|c|c|c|}
\hline Nodule ID & Cytology & $\begin{array}{l}\text { Nodule size } \\
\qquad(\mathrm{mm})\end{array}$ & $\begin{array}{c}\text { FNA broken } \\
\text { RET by FISH (\%) }\end{array}$ & $\begin{array}{l}\text { FNA RETIPTC1 } \\
\text { by RT-PCR }\end{array}$ & $\begin{array}{l}\text { FNA FISH } \\
\text { follow-up }\end{array}$ & Histology & $\begin{array}{l}\text { Post-surgery broken } \\
\text { RET by FISH }\end{array}$ \\
\hline 1 & Thy 2 & 27 & 3 & Neg & No & No surgery & \\
\hline 16 & Thy 2 & 25 & 4 & Neg & No & No surgery & \\
\hline 40 & Thy 2 & 30 & 4 & Neg & No & No surgery & \\
\hline 334 & Thy 2 & 14 & 5.30 & Neg & $5.80 \%$ & No surgery & \\
\hline 20 & Thy 2 & 22 & 5.7 & Neg & No & FTA & Neg \\
\hline 294 & Thy 2 & 18 & 8.90 & $\mathrm{Neg}^{\mathrm{b}}$ & $8.3 \%$ & No surgery & \\
\hline 26 & Thy 3 & 33 & 3 & Neg & Surgery & PTC-FV & Neg \\
\hline 323 & Thy 3 & 20 & 3 & Neg & Surgery & Benign & Neg \\
\hline 36 & Thy 3 & 38 & 3.75 & Neg & Surgery & Benign $^{c}$ & Neg \\
\hline 32 & Thy 3 & 31 & 4 & Neg & No & No surgery & \\
\hline 82 & Thy 3 & 20 & 5.30 & Neg & Surgery & Benign & Neg \\
\hline 9 & Thy 3 & 35 & 5.7 & Neg & Surgery & Benign & Neg \\
\hline 60 & Thy 4 & 26 & 25.30 & RETIPTC1 & Surgery & PTC & $19 \%$ \\
\hline 228 & Thy 5 & 30 & 8 & RETIPTC1 & Surgery & PTC & $10.30 \%$ \\
\hline 260 & Thy 5 & 24 & 6.80 & RETIPTC1 & Surgery & PTC & $8.50 \%$ \\
\hline 284 & Thy 5 & 20 & 8.8 & RETIPTC1 & Surgery & PTC & $13 \%$ \\
\hline 295 & Thy 5 & 30 & 4 & Neg & Surgery & PTC & Neg \\
\hline 13 & Thy 5 & 21 & 3.3 & Neg & Surgery & PTC-WLV & Neg \\
\hline
\end{tabular}

FTA, follicular thyroid adenoma; PTC, papillary thyroid carcinoma; PTC-FV, PTC-follicular variant.

a Follow-up at 12 months.

${ }^{\mathrm{b}}$ RETIPTC3 by FISH.

'Lesions with occult PTC; patients $=261$.

thyroid carcinomas, not corresponding to the nodules examined, were not included in the statistical analysis (Table 2). Details on the surgically removed nodules are given in the Supplementary Table 1 , see section on supplementary data given at the end of this article.

\section{FISH analysis}

Among the 281 FNA smears, a split-apart RET FISH signal was identified in 18 (6.4\%) samples; among these, the percentage of positive nuclei ranged from 3.0 to $25.3 \%$ (Table 1 and Fig. 1). Except for Thy 1, broken RET was found in all cytological classes, $3.2 \%$ in Thy $2,13 \%$ in Thy $3,6.6 \%$ in Thy 4 , and $26.3 \%$ in Thy 5 ; a percentage of broken RET-positive nuclei of $6.8 \%$ was the cutoff marking cases that were RT-PCR positive for RET/PTC.

Twelve FISH-positive nodules were surgically removed, seven of which had a final diagnosis of malignancy (PTC) while five were benign tumors. Broken RET was confirmed in four PTCs (Fig. 1A, B and Table 1). The remaining three surgically removed carcinomas (one classified as Thy 3 and two as Thy 5) were FISH negative. One of these (nodule 13, Table 1) carried the BRAF V600E mutation. The RET split percentage in corresponding cytological preparations of these three cases was $4 \%$ in one and 3\% in two. The five histologically benign nodules had a postoperative negative FISH test and had a mean of $4.7 \%$ (range $3-5.7 \%$ ) nuclei with a split-apart signal (Fig. 1C) in the corresponding FNA (one classified as Thy 2 and four as Thy 3) (Table 1). In one nodule (nodule 294, Table 1), which was negative for RET recombination by RT-PCR, a dual-color, dual-fusion approach using BAC clones containing RET and NCOA4 genes demonstrated two double red/green FISH signals, generated by the RET/PTC3 variant (Fig. 1D).

\section{RET/PTC RT-PCR}

Four of 281 nodules showed RET/PTC1 rearrangement by RT-PCR (nodules 60, 228, 260, 284; Table 1). Three belonged to Thy 5 and one to Thy 4 cytological classes and were surgically removed. They were positive for splitapart FISH signals in both cytological and histological materials. One case (nodule 294) not showing matching results between FISH analysis and RT-PCR for RET/PTC1 displayed a RET/PTC3 rearrangement using FISH.

\section{Comparison of RET rearrangements ascertained by FISH and by RT-PCR}

Histological diagnosis was available for 53 nodules including 25 benign and 28 malignant (Table 2). The diagnostic value of detecting RET abnormality was limited, either by FISH (25.0\% of malignant nodules)

Published by Bioscientifica Ltd. 
Table 2 Cytology, FISH, and RT-PCR analysis for RET rearrangement of 53 FNA with definitive diagnosis.

\begin{tabular}{|c|c|c|c|}
\hline & Histology benign & Histology malignant & \\
\hline Cytology & $n=25$ & $n=28$ & \\
\hline Thy 1 & $1(\mathrm{BN})$ & 1 (FV-PTC) & Sensitivity $75.0 \%$ \\
\hline Thy 2 & $9(5 \mathrm{BN}, 4 \mathrm{FTA})$ & 0 & Specificity $96.0 \%$ \\
\hline Thy 3 & 14 (12 BN, 2 FTA) & 6 (4 FV-PTC, 2 PTC) & PPV $95.4 \%$ \\
\hline Thy 4 & $1(\mathrm{BN})$ & 8 (5 PTC, 1 TCV-PTC, 2 FV-PTC) & NPV $77.4 \%$ \\
\hline Thy 5 & 0 & 13 (9 PTC, 3 WLV- PTC, 1 FV-PTC) & Accuracy $85.0 \%$ \\
\hline RET/PTC FISH positive $(n=12)$ & $n=5$ & $n=7$ & \\
\hline Thy 1 & 0 & 0 & Sensitivity $25.0 \%$ \\
\hline Thy 2 & $1(\mathrm{BN})$ & 0 & Specificity $80.0 \%$ \\
\hline Thy 3 & $4(3 \mathrm{BN}, 1 \mathrm{FTA})$ & 1 (FV-PTC) & PPV $58.3 \%$ \\
\hline Thy 4 & 0 & 1 (PTC) & NPV $48.8 \%$ \\
\hline Thy 5 & 0 & 5 (4 PTC, 1 WLV-PTC) & Accuracy $50.9 \%$ \\
\hline RET/PTC FISH negative $(n=41)$ & $n=20$ & $n=21$ & \\
\hline Thy 1 & $1(\mathrm{BN})$ & 1 (FV-PTC) & Sensitivity $25.0 \%$ \\
\hline Thy 2 & 8 (4 BN, 4 FTA) & 0 & Specificity $80.0 \%$ \\
\hline Thy 3 & 10 (9 BN, 1 FTA) & 5 (3 FV-PTC, 2 PTC) & PPV $58.3 \%$ \\
\hline Thy 4 & $1(\mathrm{BN})$ & 7 (4 PTC, 1 TCV-PTC, 2 FV-PTC) & NPV $48.8 \%$ \\
\hline Thy 5 & 0 & 8 (5 PTC, 2 WLV-PTC, 1 FV-PTC) & Accuracy $50.9 \%$ \\
\hline RET/PTC RT-PCR positive $(n=4)$ & $n=0$ & $n=4$ & \\
\hline Thy 1 & 0 & 0 & Sensitivity $14.3 \%$ \\
\hline Thy 2 & 0 & 0 & Specificity $100.0 \%$ \\
\hline Thy 3 & 0 & 0 & PPV $100.0 \%$ \\
\hline Thy 4 & 0 & 1 (PTC) & NPV $51.0 \%$ \\
\hline Thy 5 & 0 & 3 (3 PTC) & Accuracy $54.7 \%$ \\
\hline RET/PTC RT-PCR negative $(n=49)$ & $n=25$ & $n=24$ & \\
\hline Thy 1 & $1(\mathrm{BN})$ & 1 (FV-PTC) & Sensitivity $14.3 \%$ \\
\hline Thy 2 & $9(5 \mathrm{BN}, 4 \mathrm{FTA})$ & 0 & Specificity $100.0 \%$ \\
\hline Thy 3 & 14 (12 BN, 2 FTA) & 6 (4 FV-PTC, 2 PTC) & PPV $100.0 \%$ \\
\hline Thy 4 & $1(\mathrm{BN})$ & 7 (4 PTC, 1 TCV-PTC, 2 FV-PTC) & NPV $51.0 \%$ \\
\hline Thy 5 & 0 & 10 (6 PTC, 3 WLV-PTC, 1 FV-PTC) & Accuracy $54.7 \%$ \\
\hline
\end{tabular}

BN, benign nodule (goiter, hyperplastic nodule); FTA, follicular thyroid adenoma; FV-PTC, follicular variant of papillary thyroid carcinoma; NPV, negative predictive value; PPV, positive predictive value; PTC, papillary thyroid carcinoma; TCV-PTC, tall cell variant of PTC; WLV-PTC, Warthin-like variant of PTC.

or by RT-PCR (14.3\% of malignant nodules), and in both cases, it was markedly lower than that of conventional cytology (75.0\% of malignant nodules of the Thy 4 or Thy 5 classes). On the other hand, the specificity of RET abnormality was $100 \%$ by PCR and lower (80\%) by FISH.

\section{$B R A F^{\text {V600E }}$ quantitative RT-PCR}

Among the 281 nodules, 279 were suitable for $B R A F^{V 600 E}$ mutation investigation. The total DNA yield per sample ranged from 0.12 to $1.6 \mu \mathrm{g}$, and the $B R A F^{V 600 E}$ mutation was detected in 13 FNA (4.7\%), all of which were classified as Thy 5, representing $68.4 \%$ of the Thy 5 group (19 nodules). All patients with cytological diagnosis of a Thy 5 nodule underwent surgery. In one of them (nodule 13, Table 1), the FNA showed 3.3\% broken RET by FISH, which was not confirmed in the histological sample. No cases with simultaneous RET/PTC rearrangement and $B R A F^{V 600 E}$ mutation were observed.

\section{Discussion}

RET/PTC was the first chimeric gene with oncogenic potential described in a tumor of epithelial origin (Fusco et al. 1987, Grieco et al. 1994). Unlike the wild-type RET gene, which is not expressed in normal thyroid cells, RET/PTC is expressed in a ligand-independent manner in follicular tumor cells, in which it originates by the juxtaposition of the RET genomic region coding for the tyrosine kinase domain with the $5^{\prime}$-terminal regions of several unrelated genes. A specific pathogenetic role of the chimeric gene in a subset of PTC has long been considered a dogma in relation to its consistent activation, not only in PTC developing after high level ionizing radiation exposure but also in sporadic pediatric PTC in children not exposed to ionizing radiation (Nikiforov et al. 1997). This dogma was reinforced by demonstrations of the ability of RET/PTC to cause PTC in nude mice (Santoro et al. 1996), by its frequency in $\sim 20-40 \%$ of PTC and by its rare simultaneous occurrence with other specific

Published by Bioscientifica Ltd 

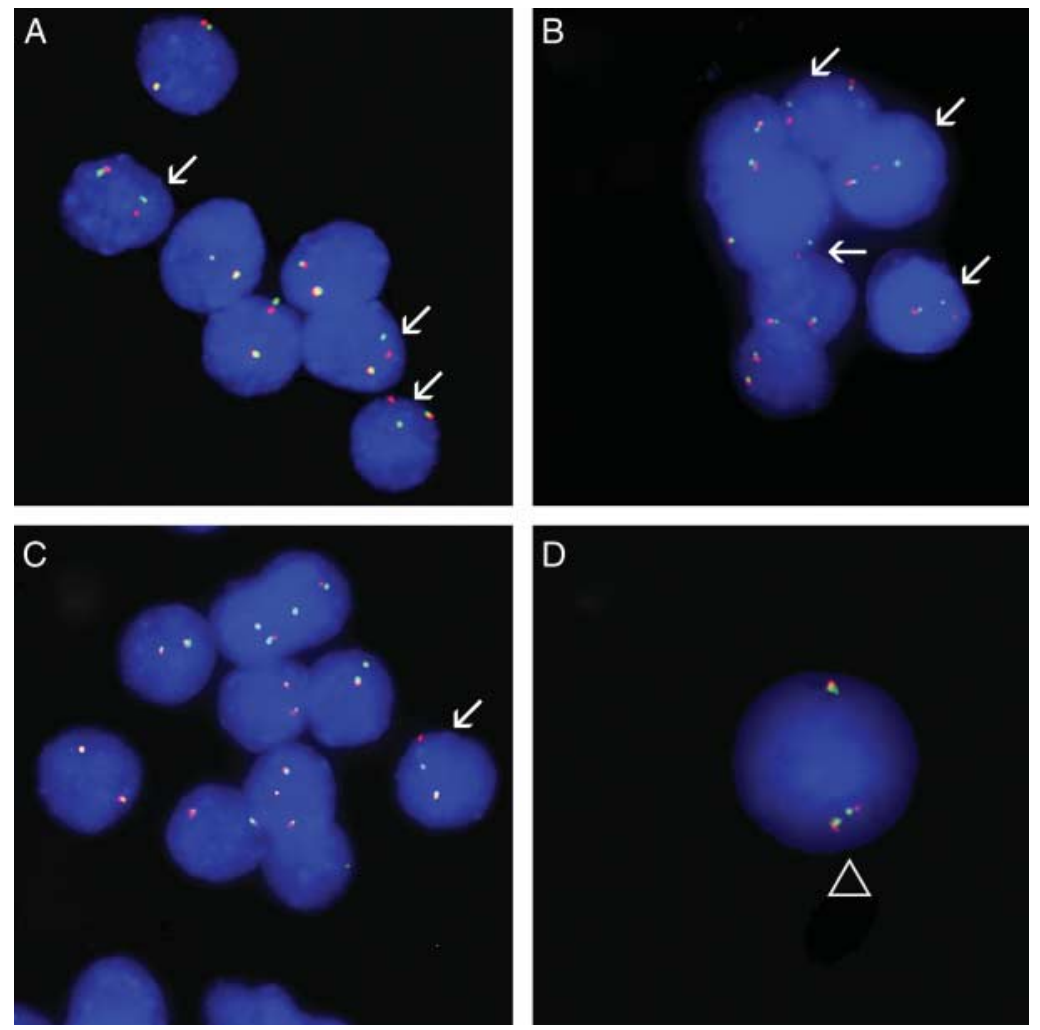

\section{Figure 1}

(A, B and C) Dual-color, break-apart RET probe hybridized on thyroid FNA cells. (A) Nodule 60 classified as Thy 4. (B) Nodule 284 classified as Thy 5. (C) Nodule 13 classified as Thy 5 . Gene breakage is shown by the split-apart $\mathrm{red} / \mathrm{green}$ signal (arrows). Note: the presence of several abnormal cells in $A$ and $B$ is representative of a clonal change, while the single abnormal cell in $\mathrm{C}$ might indicate sporadic change. (D) Dual-color, dual-fusion FISH with

alterations associated with follicular thyroid carcinoma (Caria et al. 2012). Nevertheless, the presence of RET/PTC in benign thyroid nodules (Ishizaka et al. 1991, Guerra et al. 2011) and the extent of heterogeneity observed within individual nodules (Fusco et al. 2002, Unger et al. 2004) challenge this tenet. Thus, the current challenge in using RET/PTC analysis as an adjunct to cytology involves the interpretative level of the results. Clonal or non-clonal $R E T / P T C$ rearrangement in follicular cells has been claimed to distinguish malignant from benign nodules (Marotta et al. 2011, Nikiforov \& Nikiforova 2011). A propensity of RET/PTC bearing adenomas to grow faster than RET/PTC-negative adenomas has been reported (Marotta et al. 2011), giving new emphasis to the urge for clear-cut reporting and quantification of RET/PTC changes. Distinct PCR-based methods have been shown to have varying sensitivity in revealing the abnormality (Zhu et al. 2006, Marotta et al. 2011), which is particularly crucial in testing FNA.
BAC clones containing the RET and NCOA4 genes in nodule 294 FNA classified as Thy 2 . Genes are rearranged by inversion of the chromosome band $10 q 11.2$ as indicated by the formation of two small double red/green signals (arrowhead). The close red and green signals correspond to intact RET and NCOA4 genes, closely mapping at $10 \mathrm{q} 21$.

Biologically speaking, a cell clone is defined as a cell population derived from a single parental cell. With respect to thyroid nodules, it is generally accepted that a clonal rearrangement is present in a consistent proportion of tumor cells and can be detected using various methods. In contrast, a non-clonal event occurs in a small fraction of scattered cells or in a single cell within the lesion, or even in the context of a normal thyroid, and only ultrasensitive techniques are able to reveal it. Interphase FISH is the only available technique allowing the identification of gene fusion within a single nucleus, and when applied to a tissue section, it may localize a single/sporadic event, distinguishing it from a clonal event, which is usually shared by neighboring cells. The FNA method, per se, tends to disaggregate the tissue, making it difficult to distinguish clonal from non-clonal events at the cytological level and impeding deciphering the meaning of sporadic abnormal cells. However, if nearby cells in a cytological preparation hybridized with a specific probe show the same abnormal

Published by Bioscientifica Ltd 
FISH pattern, it suggests the presence of a clonal change. In contrast, the same abnormality observed in scattered cells might indicate a sporadic or oligoclonal event. To address this issue, we established analytical specificity and cutoff values for a dual-color, break-apart home brew RET probe, which is able to identify broken $R E T$ in cells from FNA. A FISH-based threshold value of $\geq 3 \%$ was established. In our series, a total of 18 of 281 (6.4\%) FNA exceeded this cutoff (17 had RET/PTC1 oncogene and one had the RET/PTC3 variant). We observed that the percentage of FNA-positive nuclei ranged from 3.0 to $25.3 \%$, with a positive trend from Thy 2 to Thy 5 nodules (possibly biased by small number of cases with cytological subclass Thy 4). Relying on the available histology of 53 surgically removed nodules, we compared the diagnostic performance of FISH and RT-PCR (Table 2). FISH sensitivity was superior to that of RT-PCR, but RT-PCR exhibited greater specificity. Considering that RET/PTC assessed by conventional RT-PCR amplification may be indicative of the presence of a clonal change (and hence of malignancy), we determined the percentage of FISH abnormal cells that correlated with a RT-PCR-positive result. By RT-PCR, the chimeric gene product was detected only in FNA exhibiting $\geq 6.8 \%$ FISH abnormal cells, thereby establishing a FISH RT-PCR-based threshold value of $\geq 6.8 \%$, which in our laboratory setting distinguishes sporadic from clonal RET changes. Indeed, 7 of 12 surgically removed FISH abnormal nodules were malignant (PTC) and 5 were benign. Broken RET was confirmed in four surgically removed PTCs (which usually showed a higher percentage of nuclei with split-apart FISH signal than found in the corresponding FNA). The three PTCs lacking a split-apart signal in the surgical sample actually had $<6.8 \%$ positive cells in the corresponding FNA. One of these showed a $B R A F^{V 600 E}$ mutation, which indirectly confirms the $6.8 \%$ cutoff as an appropriate threshold for distinguishing non-clonal from clonal RET/PTC nodules, as BRAF ${ }^{V 600 E}$ and RET/PTC mutations are usually mutually exclusive. Only nodule 294 , a Thy 2 nodule with $\sim 8 \%$ broken RET (RET/PTC3 variant), observed at the first and 1-year follow-up examinations remains difficult to interpret.

In keeping with the results obtained from malignant nodules, none of the surgically removed nodules diagnosed as benign showed broken RET in the surgical sample. This correlates with the finding that none of the corresponding FNA exceeded the $6.8 \%$ split-apart FISH signal.

Our results establish a precise FISH abnormal threshold that refines at the single-cell level the interpretation of the heterogeneous distribution of RET/PTC rearrangements within an individual thyroid nodule. Moreover, the FISH assay was shown to be a useful adjunct to cytology, reinforcing molecular results and further indicating the low frequency of broken RET in benign nodules. FISH has proven to be more efficient in disclosing sporadic changes, when compared to RT-PCR, and validating the efficacy of RT-PCR amplification in detecting clonal RET/PTC alterations. Indeed, in our series, most surgically removed indeterminate (Thy 3 ) nodules with sporadic broken RET had a benign histological diagnosis. Follow-up of cases with borderline percentages of broken $R E T$ will clarify whether sporadic abnormal cells are prone to programmed cell death or may produce abnormal clones leading to malignancy. Furthermore, our findings support the capability of a RET break-apart probe not only to discriminate between clonal and oligoclonal/sporadic changes but also to disclose RET/PTC variants. Finally, our study indicates that FISH in combination with FNA may be useful as a research tool in the ongoing analysis of the role of RET/PTC oncogene as a driver or passenger event in PTC development.

\section{Supplementary data}

This is linked to the online version of the paper at http://dx.doi.org/10.1530/ ERC-13-0157.

\section{Declaration of interest}

The authors declare that there is no conflict of interest that could be perceived as prejudicing the impartiality of the research reported.

\section{Funding}

This work was partially supported by the Italian Ministry of University and Research (PRIN grant no. 2007MBW5M7), the Regione Autonoma Sardegna (grant no. CRP1-63), and Fondazione Banco Sardegna (grant no. $1282 / 2010-1132)$

\section{References}

Adeniran AJ, Zhu Z, Gandhi M, Steward DL, Fidler JP, Giordano TJ, Biddinger PW \& Nikiforov YE 2006 Correlation between genetic alterations and microscopic features, clinical manifestations, and prognostic characteristics of thyroid papillary carcinomas. American Journal of Surgical Pathology 30 216-222. (doi:10.1097/01.pas. 0000176432.73455.1b)

Ali SZ, Fish SA, Lanman R, Randolph GW \& Sosa JA 2013 Use of the Afirma ${ }^{\circledR}$ gene expression classifier for preoperative identification of benign thyroid nodules with indeterminate fine needle aspiration cytopathology. PLoS Currents. (doi:10.1371/currents.eogt. e557cbb5c7e4f66568ce582a373057e7)

Arora N, Scognamiglio T, Zhu B \& Fahey TJ, III 2008 Do benign thyroid nodules have malignant potential? An evidence-based review World Journal of Surgery 32 1237-1246. (doi:10.1007/s00268-008-9484-1) 
Boi F, Lai ML, Marziani B, Minerba L, Faa G \& Mariotti S 2005 High prevalence of suspicious cytology in thyroid nodules associated with positive thyroid autoantibodies. European Journal of Endocrinology 153 637-642. (doi:10.1530/eje.1.02020)

Caria P \& Vanni R 2010 Cytogenetic and molecular events in adenoma and well-differentiated thyroid follicular-cell neoplasia. Cancer Genetics and Cytogenetics 203 21-29. (doi:10.1016/j.cancergencyto.2010.08.025)

Caria P, Dettori T, Frau DV, Di Oto E, Morandi L, Parmeggiani A, Tallini G \& Vanni R 2012 Simultaneous occurrence of PAX8-PPARg and RET-PTC3 rearrangements in a follicular variant of papillary thyroid carcinoma. American Journal of Surgical Pathology 36 1415-1420. (doi:10.1097/ PAS.0b013e318264bdd6)

Cooper DS, Doherty GM, Haugen BR, Kloos RT, Lee SL, Mandel SJ, Mazzaferri EL, McIver B, Pacini F, Schlumberger M et al. 2009 Revised American Thyroid Association management guidelines for patients with thyroid nodules and differentiated thyroid cancer: The American Thyroid Association (ATA) Guidelines Taskforce on Thyroid Nodules and Differentiated Thyroid Cancer. Thyroid 19 1167-1214. (doi:10.1089/thy.2009.0110)

Drieschner N, Rippe V, Laabs A, Dittberner L, Nimzyk R, Junker K, Rommel B, Kiefer Y, Belge G, Bullerdiek J et al. 2011 Interphase fluorescence in situ hybridization analysis detects a much higher rate of thyroid tumors with clonal cytogenetic deviations of the main cytogenetic subgroups than conventional cytogenetics. Cancer Genetics 204 366-374. (doi:10.1016/j.cancergen.2011.03.008)

Fagin JA 2004 Challenging dogma in thyroid cancer molecular genetics role of RET/PTC and BRAF in tumor initiation. Journal of Clinical Endocrinology and Metabolism 89 4264-4266. (doi:10.1210/jc. 2004-1426)

Ferraz C, Rehfeld C, Krogdahl A, Precht Jensen EM, Bösenberg E, Narz F, Hegedüs L, Paschke R \& Eszlinger M 2012 Detection of PAX8/PPARG and RET/PTC rearrangements is feasible in routine air-dried fine needle aspiration smears. Thyroid 10 1025-1030. (doi:10.1089/thy.2011.0391)

Frau DV, Erdas E, Caria P, Ambu R, Dettori T, Faa G, Fletcher CD \& Vanni R 2010 Deep fibrous histiocytoma with a clonal karyotypic alteration: molecular cytogenetic characterization of a $\mathrm{t}(16 ; 17)(\mathrm{p} 13.3 ; \mathrm{q} 21.3)$. Cancer Genetics and Cytogenetics 202 17-21. (doi:10.1016/j.cancergencyto.2010.06.012)

Fusco A, Grieco M, Santoro M, Berlingieri MT, Pilotti S, Pierotti MA, Della Porta G \& Vecchio G 1987 A new oncogene in human thyroid papillary carcinomas and their lymph-nodal metastases. Nature 328 170-172. (doi:10.1038/328170a0)

Fusco A, Chiappetta G, Hui P, Garcia-Rostan G, Golden L, Kinder BK, Dillon DA, Giuliano A, Cirafici AM, Santoro M et al. 2002 Assessment of RET/PTC oncogene activation and clonality in thyroid nodules with incomplete morphological evidence of papillary carcinoma: a search for the early precursors of papillary cancer. American Journal of Pathology 160 2157-2167. (doi:10.1016/S0002-9440(10)61164-9)

Grieco M, Cerrato A, Santoro M, Grieco M, Cerrato A, Santoro M, Fusco A, Melillo RM \& Vecchio G 1994 Cloning and characterization of H4 (D10S170), a gene involved in RET rearrangements in vivo. Oncogene 9 2531-2535.

Guerra A, Sapio MR, Marotta V, Campanile E, Moretti MI, Deandrea M, Motta M, Limone PP, Fenzi G, Rossi G et al. 2011 Prevalence of RET/PTC rearrangement in benign and malignant thyroid nodules and its clinical application. Endocrine Journal 58 31-38. (doi:10.1507/endocrj. K10E-260)

Guerra A, Sapio MR, Marotta V, Campanile E, Rossi S, Forno I, Fugazzola L, Budillon A, Moccia T, Fenzi G et al. 2012 The primary occurrence of $\mathrm{BRAF}(\mathrm{V} 600 \mathrm{E})$ is a rare clonal event in papillary thyroid carcinoma. Journal of Clinical Endocrinology and Metabolism 97 517-524. (doi:10.1210/jc.2011-0618)

Hieber L, Huber R, Bauer V, Schäffner Q, Braselmann H, Thomas G, Bogdanova T \& Zitzelsberger H 2011 Chromosomal rearrangements in post-Chernobyl papillary thyroid carcinomas: evaluation by spectral karyotyping and automated interphase FISH. Journal of Biomedicine and Biotechnology 2011 693691. (doi:10.1155/2011/693691)

Hodak SP, Rosenthal DS \& For The American Thyroid Association Clinical Affairs Committee 2013 Information for clinicians: commercially available molecular diagnosis testing in the evaluation of thyroid nodule FNA specimens. Thyroid 23 131-134. (doi:10.1089/ thy.2012.0320)

Ishizaka Y, Kobayashi S, Ushijima T, Hirohashi S, Sugimura T \& Nagao M 1991 Detection of retTPC/PTC transcripts in thyroid adenomas and adenomatous goiter by an RT-PCR method. Oncogene 6 1667-1672.

Kim H, Yoo SB, Choe JY, Paik JH, Xu X, Nitta H, Zhang W, Grogan TM, Lee CT, Jheon $S$ et al. 2006 Detection of ALK gene rearrangement in non-small cell lung cancer: a comparison of fluorescence in situ hybridization and chromogenic in situ hybridization with correlation of ALK protein expression. Journal of Thoracic Oncology 6 1359-1366. (doi:10.1097/JTO.0b013e31821cfc73)

Marotta V, Guerra A, Sapio MR \& Vitale M 2011 RET/PTC rearrangement in benign and malignant thyroid diseases: a clinical standpoint. European Journal of Endocrinology 165 499-507. (doi:10.1530/EJE-11-0499)

Mehta V, Nikiforov YE \& Ferris RL 2012 Use of molecular biomarkers in FNA specimens to personalize treatment for thyroid surgery. Head \& Neck [in press]. (doi:10.1002/hed.23140)

Nakazawa T, Murata S, Kondo T, Niu D, Mochizuki K, Kawasaki T, Yamane T, Nakamura N \& Katoh R 2009 RET/PTC rearrangements arising from a small population of papillary thyroid carcinoma cells, possible candidate for passenger mutation. Virchows Archiv 455 35-41. (doi:10.1007/s00428-009-0789-8)

Nikiforov YE 2006 RET/PTC rearrangement - a link between Hashimoto's thyroiditis and thyroid cancer...or not. Journal of Clinical Endocrinology and Metabolism 91 2040-2042. (doi:10.1210/jc.2006-0791)

Nikiforov YE \& Nikiforova MN 2011 Molecular genetics and diagnosis of thyroid cancer. Nature Reviews. Endocrinology 7 569-580. (doi:10.1038/ nrendo.2011.142)

Nikiforov YE, Rowland JM, Bove KE, Monforte-Munoz H \& Fagin JA 1997 Distinct pattern of ret oncogene rearrangements in morphological variants of radiation-induced and sporadic thyroid papillary carcinomas in children. Cancer Research 57 1690-1694.

Petersen BL, Sørensen MC, Pedersen S \& Rasmussen M 2004 Fluorescence in situ hybridization on formalin-fixed and paraffin-embedded tissue: optimizing the method. Applied Immunohistochemistry \& Molecular Morphology 12 259-265. (doi:10.1097/00129039-200409000-00013)

Rhoden KJ, Unger K, Salvatore G, Yilmaz Y, Vovk V, Chiappetta G, Qumsiyeh MB, Rothstein JL, Fusco A, Santoro M et al. 2006 RET/papillary thyroid cancer rearrangement in nonneoplastic thyrocytes: follicular cells of Hashimoto's thyroiditis share low-level recombination events with a subset of papillary carcinoma. Journal of Clinical Endocrinology and Metabolism 91 2414-2423. (doi:10.1210/ jc.2006-0240)

Santoro M, Chiappetta G, Cerrato A, Salvatore D, Zhang L, Manzo G, Picone A, Portella G, Santelli G, Vecchio G et al. 1996 Development of thyroid papillary carcinomas secondary to tissue-specific expression of the RET/PTC1 oncogene in transgenic mice. Oncogene 12 1821-1826.

Santoro M, Melillo RM \& Fusco A 2006 RET/PTC activation in papillary thyroid carcinoma. European Journal of Endocrinology 155 645-653. (doi:10.1530/eje.1.02289)

Unger K, Zitzelsberger H, Salvatore G, Santoro M, Bogdanova T, Braselmann H, Kastner P, Zurnadzhy L, Tronko N, Hutzler P et al. 2004 Heterogeneity in the distribution of RET/PTC rearrangements within individual post-Chernobyl papillary thyroid carcinomas. Journal of Clinical Endocrinology and Metabolism 89 4272-4279. (doi:10.1210/ jc.2003-031870)

Wiktor AE, Van Dyke DL, Stupca PJ, Ketterling RP, Thorland EC, Shearer BM, Fink SR, Stockero KJ, Majorowicz JR \& Dewald GW 2006 Preclinical validation of fluorescence in situ hybridization assays for 
clinical practice. Genetics in Medicine 8 16-23. (doi:10.1097/01.gim. 0000195645.00446.61)

Wolff DJ, Bagg A, Cooley LD, Dewald GW, Hirsch BA, Jacky PB, Rao KW \& Rao PN 2007 Guidance for fluorescence in situ hybridization testing in hematologic disorders. Association for Molecular Pathology Clinical Practice Committee; American College of Medical Genetics Laboratory Quality Assurance Committee. Journal of Molecular Diagnostics 9 134-143. (doi:10.2353/jmoldx.2007.060128)
Xing M 2007 BRAF mutation in papillary thyroid cancer: pathogenetic role, molecular bases, and clinical implications. Endocrine Reviews 28 742-762. (doi:10.1210/er.2007-0007)

Zhu Z, Ciampi R, Nikiforova MN, Gandhi M \& Nikiforov YE 2006 Prevalence of RET/PTC rearrangements in thyroid papillary carcinomas: effects of the detection methods and genetic heterogeneity. Journal of Clinical Endocrinology and Metabolism 91 3603-3610. (doi:10.1210/jc.2006-1006)

Received in final form 23 May 2013

Accepted 30 May 2013

Made available online as an Accepted Preprint

20 May 2013
Published by Bioscientifica Ltd. 